\title{
ŽENSKE/RODNE STUDIJE I PROBLEMI DISCIPLINIZACIJE: ULOGA ČASOPISA
}

Sonji Drljević, bez koje ne bi bilo Ženskih studija

U ovom tekstu opisuje se istorija nastanka Centra za ženske studije u Beogradu i časopisa Ženske studije (1995-2002). Analizira se uređivačka politika časopisa, kao i njegova uloga u legitimizaciji ženskog znanja i iskustva. Feministički časopisi se vide kao promoteri feminističke teorije na post-jugoslovenskom prostoru. Ukazuje se na značaj časopisa u procesu institucionalizacije i disciplinizacije programa ženskih/rodnih studija. Uporedo sa domaćim časopisom, analizira se uređivačka politika časopisa European Journal of Women's Studies.

Ključne reči: Ženske studije, European Journal of Women's Studies, ženske/rodne studije kao "interdisciplinarna disciplina”, feministički časopisi, uređivačka politika 


\section{ŽENSKE STUDIJE: O AKTIVIZMU I TEORIJI}

Kada je 1992. godine osnovan Centar za ženske studije, u Beogradu je

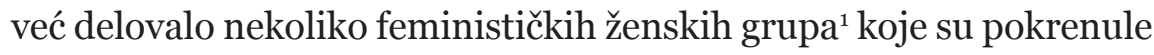
ozbiljnu izdavačku delatnost. Njihov fokus bio je na specifičnoj kombinaciji ženskog aktivizma i feminističke teorije. Jaka teorijska svest karakteriše jugoslovensku feminističku scenu još od kraja sedamdesetih godina, te se u okviru nje nisu samo prevodili značajni tekstovi, već se i razvijala domaća teorijska misao. ${ }^{2}$ Ta teorija bila je povezana i sa jasno izraženom aktivističkom komponentom. Odnos teorijskog i aktivističkog, kao i dominantni modeli rada u različitim jugoslovenskim ženskim centrima donekle su se razlikovali, ali su svi ti centri bili tesno međusobno povezani i u osnovi pripadali jednoj široj sceni na kojoj je postojala bliska saradnja. Lina Vušković i Sofija Trivunac, opisujući istoriju grupe "Žena i društvo", koja je u sedamdesetim i osamdesetim godinama predstavljala jezgro okupljanja beogradskih feministkinja i feminista, naglašavaju njen antiinstitucionalni i antihijerarhijski karakter: "[N]aša grupa je bila anarhična u najboljem smislu te reči i veoma demokratična. (...) Zagrepčanke su se više bavile teorijom, pisale su radove, a mi smo uglavnom diskutovale, govorile smo o svom iskustvu i razvijale samosvest."

Skoro istovetnu rečenicu čula sam više puta od Sonje Drljević, jedne od osnivačica Centra za ženske studije u Beogradu, koja je svojom upornošću i snagom i pokrenula projekat Centra. Centar je krenuo sa predavačkim programom 1992. godine, kada su Sonja Drljević i Daša Duhček organizovale prvi tečaj ženskih studija, koji je simbolički počeo 8. marta 1992. godine. Već iduće godine, predavački program postaje dvosemestralni, a Centar se registruje kao udruženje građanki, odnosno, izvanakademska obrazovna institucija. ${ }^{4}$ Sonja Drljević još tada zagovara i pokretanje časopisa koji bi omogućio da Centar bude ne samo mesto prenosa znanja već i mesto na kome se podržavaju istraživanja i razvoj teorijskog mišljenja. Za nju, Centar koji bi

1 Za iscrpan pregled situacije videti zbornik tekstova Ka vidljivoj ženskoj istoriji: Ženski pokret u Beogradu 9o-tih, prir. Marina Blagojević (Beograd: Centar za ženske studije, istraživanje i komunikaciju, 1998).

2 Sažet pregled tog razvoja moguće je naći u izvrsnom problemskom radu Biljane Kašić i Sandre Prlende "Yugoslav Feminists in Socialism", Genero, broj 19, str. 27-48, https://www.ceeol.com/search/article-detail?id=478515, pristupljeno 12. 04. 2018.

3 Lina Vušković, Sofija Trivunac, "Feministička grupa Žena i društvo”, u: Ka vidljivoj ženskoj istoriji: Ženski pokret u Beogradu 9o-tih, prir. Marina Blagojević, str. 47.

4 Videti: Biljana Dojčinović, “Centar za ženske studije”, Ka vidljivoj ženskoj istoriji: Ženski pokret u Beogradu 9o-tih, prir. Marina Blagojević, str. 207. 
istovremeno prenosio i proizvodio znanje bio bi pre svega neophodna podrška aktivizmu. Ona je jasno videla suštinsku povezanost ta dva pola, aktivizma i akademizma. Ovde treba napomenuti da je ženske studije od njihovog osnivanja, dakle, još od sredine sedamdesetih godina kada su počeli prvi kursevi koji su se bavili ženskim temama iz feminističke perspektive u SAD-u, pratila debata o opravdanosti njihove institucionalizacije, odnosno disciplinizacije. U prvom planu bilo je pitanje odnosa između feminističke teorije i aktivizma: da li ulaskom na univerzitet i prihvatanjem univerzitetskih načela feminizam gubi svoju političku oštricu? Ta debata se kasnije prenela i u Evropu, a početkom devedesetih godina postala je značajna za takozvane zemlje u tranziciji, koje su se ubrzano otvarale prema drugom talasu feminizma.

Upućujući na vezu između teorijskog mišljenja i praktičnog delovanja, Sonja Drljivić je zapravo nastavljala tradiciju jugoslovenskog feminizma drugog talasa, koji je tu vezu uspešno negovao. Dok je $\mathrm{u}$ Jugoslaviji feminizam ostao zatvoren u relativno uskom krugu, ${ }^{5}$ politička kriza sa kraja osamdesetih godina i ratovi za nasleđe Jugoslavije u ranim devedesetim godinama doveli su do naglog otvaranja i razvoja većeg broja ženskih i feminističkih grupa širom nekadašnjeg jugoslovenskog prostora. U tom smislu, početak devedesetih pokazuje se kao vreme zamaha feminizma, koji nasuprot horskom i državno orkestriranom nacionalizmu i ratnohuškačkom diskursu u javnoj sferi, artikuliše alternativnu feminističku, antiratnu i antinacionalističku poziciju koja iznova, u drugačijim okolnostima, povezuje aktivizam i teorijsko mišljenje.

To je istovremeno značilo da su feminističke aktivnosti, kao i feministička teorija, bili isključeni iz medija glavnog toka koji su oblikovali javni prostor. Odgovor ženskih grupa na takvu situaciju bilo je povezivanje sa drugim alternativnim, opozicionim pokretima, s jedne strane, te pokretanje sopstvenih izdavačkih projekata, s druge. Dubravka Đurić u opisu feminističke izdavačke delatnosti u devedesetim godinama navodi više značajnih feminističkih izdanja, časopisa i zbornika u kojima ženske grupe objavljuju tekstove o svojim aktivnostima, kao i značajne teorijske tekstove. Tu su, pre svega, Feminističke sveske

5 Za detaljniju istoriju jugoslovenskog feminizma u sedamdesetim i osamdesetim godinama videti Lepa Mlađenović, "Počeci feminizma - Ženski pokret u Beogradu, Zagrebu, Ljubljani”, http://www.womenngo.org.rs/zenski-pokret/istorija-zenskog-pokreta/217-poceci-feminizma-zenski-pokret-u-beogradu-zagrebu-ljubljani; Zsofia Lorand, "Learning a Feminist Language: The Intellectual History of Feminism in Yugoslavia in the 1970s and 1980s", doktorska teza, Central European University, 2015. 
koje izdaje Autonomni ženski centar, koji je izdavačku delatnost započeo objavljujući prvo svoj Bilten i Antiratni bilten SOS-a od 1990, a potom važan zbornik Žene za žene - protesti, apeli, izjave, informacije autonomnih ženskih inicijativa (1993); od 1994. godine AŽC počinje sa redovnim objavljivanjem časopisa Feminističke sveske u kom se nalaze vrlo različiti tipovi tekstova, od izveštaja o akcijama Centra i svedočanstava o ženskim iskustvima, posebno u ratu, do intervjua sa značajnim akterima civilne scene i teorijskih tekstova. Žene u crnom od 1993. godine redovno objavljuju godišnjak Žene za mir, a 1994. godine pokreću i časopis Žene protiv rata. U zimu 1994-5. počinje da izlazi i ProFemina, časopis za žensku književnost $i$ kulturu u izdanju tada opozicionog Radija B92. ${ }^{6}$ Osim ProFemine, koja je praktično pokrenuta u isto vreme kada i Ženske studije, svi se ovi ženski časopisi i izdanja distribuiraju neformalno i deo su alternative scene civilnog društva. To je neposredni okvir u kojem se beogradski Centar za ženske studije odlučuje za pokretanje novog časopisa, dakle, usred teške društvene krize i ratova na prostoru Jugoslavije, ali i u trenutku u kom su i ženski pokret i pitanja feminističke teorije zapravo vrlo živi i prisutni na kulturnoj sceni. Svoje mesto na toj sceni novi časopis je video u posebnom pristupu pitanjima feminizma: kao izdanje Centra, to je pre svega trebalo da bude akademski časopis posvećen pitanjima feminističke teorije.

Ovde se vredi na kratko vratiti osnivanju Centra za ženske studije i njegovoj inicijalnoj ulozi. Centar je bio osnovan kao izvanakademska institucija, a njegove su članice od početka videle Centar kao sredstvo legitimizacije ženskog znanja, pa tako i sredstvo moguće disciplinizacije u akademskim okvirima. Ta se ideja odražavala u načinu na koji su koncipirani predavački programi Centra, koji su pravljeni tako da upute polaznike u ključne pojmove i probleme feminističke teorije, kao i načine na koje je feminizam intervenisao u nekima od akademskih disciplina, poput filozofije, književne teorije, antropologije, političkih nauka, prava, istorije, kulturnih studija. I od predavačica i od polaznica očekivalo se da zadovolje akademske standarde koje se Centar trudio da uskladi sa standardima predavanja na odgovarajućim odsecima Beogradskog univerziteta, kao i sa standardima predavanja u okviru akademskih programa Ženskih studija sa kojima su članice Centra bile upoznate preko svojih profesionalnih kontakata. Drugim rečima, namera Centra bila je da proizvodi žensko znanje i da to znanje legitimiše na akademskom nivou.

6 Dubravka Đurić, “Feministička izdavačka delatnost”, u: Ka vidljivoj ženskoj istoriji: Ženski pokret u Beogradu 9o-tih, prir. Marina Blagojević, str. 303-10. 
Pokretanje časopisa bilo je deo tog projekta. U trenutku kada je časopis planiran i pripreman, tokom 1994. godine, činilo se da intervencijom u javni prostor možemo da proizvedemo pritisak na akademske strukture koji bi bio dovoljno jak da promeni odnos prema ženskim studijama i otvori prostor za novu disciplinu. Ovde se vredi prisetiti da je pitanje disciplinizacije ženskih studija, odnosno studija roda, bilo otvarano na različite načine u različitim evropskim zemljama i da su načini pristupanja tom pitanju u velikoj meri zavisili od akademske tradicije i njene fleksibilnosti u svakoj pojedinoj zemlji.7 U načelu, rasprave su se vodile oko toga da li ženske studije treba uvoditi kroz postojeće discipline, preko posebnih tema i metoda istraživanja, ili one treba da budu institucionalizovane kao zasebna disciplina. ${ }^{8}$ Beogradski Centar za ženske studije priklonio se viđenju prema kome ženske studije treba da budu prepoznate kao zasebna disciplina upravo zbog legitimizacijskog potencijala koji takvo stanovište nosi sa sobom: vidljivosti znanja koje se proizvodi unutar polja istraživanja i odgovarajućeg društvenog uticaja koji iz te vidljivosti proizlazi.

Vredi stoga navesti definiciju discipline na koju sam se pozvala i u jednom ranijem tekstu o disciplinizaciji ženskih studija:

Discipline su vrsta kolektiviteta koji uključuje veliki deo ljudi koji imaju diplome s istim prepoznatljivim specijalizirajućim imenom, koje su delom organizovane u celine koje onda nude pozicije za sticanje diploma i određenu moć osobama koje te diplome poseduju; osobe koje poseduju diplome te posebne specijalizovane vrste zapošljavaju se na pozicijama koje im na osnovi te diplome daju određenu moć, tako da tu zapravo postoji razmena studenata između različitih institucija koje daju diplome u području koje je prepoznato kao ista specijalizacija. ${ }^{9}$

U prethodnoj analizi ove Tarnerove definicije bilo mi je značajno pitanje "moći”, odnosno prava koja disciplinizacijom određenog područja

7 Tim se pitanjem bavio istraživački projekat Changing Knowledge and Disciplinary Boundaries Through Integrative Research Methods in the Social Sciences and Humanities, https://www.york.ac.uk/res/researchintegration/.

$8 \mathrm{O}$ tom problemu pisala sam u tekstu nastalom povodom desete godišnjice zagrebačkog Centra za ženske studije. Videti: "Ženski studiji kao mjesto susretanja/ presjeka disciplina”, Treća 1-2, Vol. VII, 2005, str. 286-93. http://zenstud.hr/wpcontent/uploads/2017/o1/Treca_br2_2005.pdf, pristupljeno 12. 04. 2018.

9 Stephen Turner, "What are Disciplines? And How Is Interdisciplinarity Different?", Practicing Interdisciplinarity, eds. Peter Weingart, Nico Stehr (Toronto: University of Toronto Press, 2000), str. 47. 
istraživanja stiču oni koji imaju diplome kojima se potvrđuje njihovo znanje iz te oblasti. Godine 1992, kada je osnivan beogradski Centar za ženske studije, i nešto kasnije, 1995. godine, kada je osnovan zagrebački Centar za ženske studije, činilo se da je pitanje disciplinizacije zaista pitanje (ne više tako dugog) vremena koje će biti potrebno da ova dva Centra, umesto sertifikata, počnu da izdaju priznate akademske diplome na osnovu kojih će njihovi vlasnici moći da dobijaju posao u struci. To se pokazalo kao, očito, neutemeljeni optimizam, ali ne zbog akademskog kvaliteta programa ili kadrova koji su se bavili ženskim studijama i rodnim studijama, već pre svega zbog nezainteresovanosti akademskih struktura da prepoznaju rodne studije kao akademsku, "interdisciplinarnu disciplinu".

Ovde, međutim, želim više da se pozabavim jednim drugim problemom koji se u većoj meri tiče pitanja feminističke periodike. Na početku navedene definicije Tarner kaže da su discipline "vrsta kolektiviteta", pri čemu je priznavanje diploma samo deo procesa građenja tog kolektiviteta. Časopisi i profesionalna udruženja takođe su važan deo tog procesa jer omogućavaju artikulaciju, javnu dostupnost i validaciju znanja u jednoj oblasti. U tom smislu, uloga časopisa Ženske studije bila je od početka povezana i sa složenim procesima moguće disciplinizacije ženskih studija kroz podršku oblikovanju kolektiviteta subjekata koji aktivno rade u tom području. Otuda i politika imenovanja časopisa, koji je dobio isto ime kao i Centar - Ženske studije. U vreme osnivanja Centra, i kasnije časopisa, pojam roda je već bio prihvaćen u feminističkoj teoriji i, kako pokazuje Imenik rodnih studija i ženskih studija zemalja Centralne i istočne Evrope, bivšeg Sovjetskog Saveza i Mongolije,$^{10}$ mnoge nove inicijative opredeljivale su se za naziv "rodne studije", koji postepeno potiskuje naziv "ženske studije". ${ }^{11}$ I u Beogradu i u Zagrebu, međutim, odluka je bila da se ostane pri nazivu "ženski”, pošto su oba projekta nastojala da se u prvi plan stavi njihov emancipatorski potencijal. Nema sumnje da je ta odluka bila politički važna u trenutku kada je ceo postjugoslovenski prostor proživljavao jednu vrstu istorijske regresije, ili bolje rečeno, repatrijarhalizacije o kojoj je Žarana Papić govorila kao o "patrijarhal-

10 Gender Studies \& Women's Studies Directory, Countries of Central \& Eastern Europe, the former Soviet Union \& Mongolia, Budapest: Open Society, 1999.

11 Neću ovde ulaziti u složene debate oko imenovanja, koje su uključivale vrlo različite argumente, od toga da se preko pojma roda naglašava teorijska utemeljenost studija, do toga da se time prevazilaze ograničenja i opasnosti od teorijskog esencijalizma koje usredsređenost isključivo na žene (uz pitanje kako ih definisati) nosi sa sobom. 
noj rekolonijalizaciji ženskih tela", koja je bila od središnje važnosti za "postkomunističke procese 'demokratske' tranzicije". ${ }^{12}$ Sistematsko potiskivanje žena iz javne sfere, nejednake plate za isti rad, uporni pokušaji da se dovedu u pitanje ženska reproduktivna prava - da pomenem samo neke od aktuelnih problema sa kojima se suočavaju žene danas - svedoče o tome da patrijarhalna rekolonizacija ženskih tela i dalje ostaje jedna od bitnih odlika društva u kom živimo.

\section{ČASOPIS "ŽENSKE STUDIJE" I PROBLEMI DISCIPLINIZACIJE} Časopis Ženske studije počeo je da izlazi 1995. godine i pod tim nazivom izlazio je do 2002. godine. Ukupno je objavljeno 15 brojeva, nakon čega je, sa promenom redakcije, promenjen i naziv časopisa u Genero, sa namerom da se pojam "ženski" zameni pojmom "gender" odnosno "rod". Redakciju časopisa činile su stalne članice Centra za ženske studije: Branka Arsić, Jasmina Lukić (glavna i odgovorna urednica), Zorica Mršević i Žarana Papić. ${ }^{13}$ Časopis je objavljivao prevode stranih teorijskih tekstova i originalne radove domaćih autorki. Svaki od objavljenih brojeva imao je glavnu temu za koju su se, po pravilu, vezivali prevedeni tekstovi, dok je domaća produkcija objavljivana u zavisnosti od materijala koji je pristizao u redakciju. Članice redakcije su naručivale tekstove od domaćih autorki - izbor tema bio je potpuno otvoren, dok su prevodi uglavnom bili vezani za glavnu temu broja. ${ }^{14}$

12 Žarana Papić, "Women in Serbia: Post-Communism, War, and Nationalist $\mathrm{Mu}$ tations", u: Sabrina Ramet, ed., Gender Politics in The Western Balkans, Philadelphia: The Pennsylvania University Press, 1999, str. 153.

13 Jasmina Lukić bila je glavna i odgovorna urednica u periodu 1995-200o. godine, dakle, u 13 brojeva časopisa Ženske studije. Branka Arsić preuzima tu ulogu u poslednja dva broja časopisa (dvobroj 14-15), u periodu 2000-2002. U tom dvobroju, redakciju čine Jasmina Lukić (zamenica glavne urednice), Zorica Mršević, Žarana Papić i Tatjana Rosić-Ilić.

14 U prvom broju časopisa objavljen je temat "Politički subjekt u savremenim feminističkim teorijama”, koji je priredila Daša Duhaček. Pored uvodnog teksta Daše Duhaček, temat je uključivao i prevedene tekstove Lis Irigarai, Rozi Brajdoti, Kerol Pejtmen, Nensi Hartsok, Džudit Batler i Šantal Muf. U broju su pored toga objavljeni i autorski tekstovi Žarane Papić “Opozicija priroda/ kultura kao 'prirodna' definicija i interpretacija polne razlike - Levi-Strosova projekcija iskona kulture kao društvenog ugovora između muškaraca”, Svenke Savić “Jezik i pol (I) istraživanja u svetu”, Zorice Mršević "Žene u zatvoru”, Biljane Dojčinović-Nešic "Li Ćindžao - okolnosti, vreme i delo". Casopis je doneo i beleške o autorkama, što je ostala trajna rubrika u svim brojevima. U dvobroju 2-3, Branka Arsić je priredila temat "Fragmenti jedne moguce istorije tela“; pored njenog uvodnika i još jednog priloga u tematu, objavljeni su još i tekstovi Nikol Loro, Floran Dipon, Ksenije Bilbije, Đulija Sisa, Lis Irigarai, Tomasa Lakera, Mardžori Garber, Done Haravej i Žan-Fransoa Liotara. U broju su objavljena i četiri rada domaćih autorki: tekst Jasmine Lukić "Ljubić 
U 13 objavljenih brojeva, dostupnih na internet stranici Centra, Ženske studije su objavile oko četrdeset originalnih tekstova domaćih autorki i autorki sa prostora Jugoslavije. Među njima su, pored Daše Duhaček, Žarane Papić, Svenke Savić, Zorice Mršević, Jasmine Lukić, Biljane Dojčinović, Branke Arsić, Vesne Nikolić Ristanović, Dubravke Đurić, čiji se tekstovi i prikazi pojavljuju u prva tri broja časopisa, bile i Anđelka Milić, Vladislava Gordić, Radmila Nastić, Darja Zaviršek, Tanja Mastnak, Katarina Vešović, Elizabeta Šeleva i Jasna Koteska.

Ako časopis posmatramo kao instrument za proizvodnju i legitimizaciju ženskog znanja, onda se iz današnje perspektive kao bitne pojavljuju dve važne odlike. Prva se tiče teorijskog utemeljenja i prevodne literature, a druga uređivačke politike vezane za domaću produkciju. Kada je reč o prevodnoj literaturi, časopis je očito imao dva utemeljenja. Na jednoj strani su bile saradnice Centra koje su bile više okrenute ka savremenoj anglo-američkoj literaturi, poput Daše Duhaček i Biljane Dojčinović, gde bih i sebe svrstala, a na drugoj autorke poput Branke Arsić, koja je bila snažno vezana za francusku teorijsku misao i filozofsku tradiciju. Zaposlena kao asistentkinja na Filozofskom fakultetu u Beogradu, gde nije mogla da se bavi feminističkom teorijom, Branka Arsić je bila vrlo angažovana na oblikovanju časopisa, što se vidi i po broju temata koje je ona priredila, kao i njenih autorskih priloga. Svojim radom, ona je insistirala na važnoj temi odnosa feminizma i dekonstrukcije i tako učinila časopis aktuelnim u tom pogledu. I francuska i anglo-američka feministička teorija bile su prevashodno uvedene iz perspektive filozofije i književne teorije, dakle onih disciplina koje su u to vreme imale posebnu važnost $\mathrm{u}$

kao arhetipski žanr” o prozi Dubravke Ugrešić, nastavak rada Svenke Savić “Jezik i pol (II) istraživanja kod nas”, kao i studije Vesne Nikolić-Ristanović “(Bez)smisao kazne zatvora ili ka feminističkoj analizi kazne" i Dubravke Đurić "Feministička umetnost”. Objavljena su i dva prikaza knjiga: Gordana Vuksanović recenzirala je knjigu Anđelke Milić: “Žene, politika, porodica”, a Leposava Kron knjigu Zorice Mršević: “Ženska prava su ljudska prava”. Neću dalje navoditi sadržaj brojeva Ženskih studija jer je 13 brojeva dostupno na sajtu Centra (http://www.zenskestudie.edu. rs/izdavastvo/elektronska-izdanja/casopis-zenske-studije). Ovde će biti dovoljno da dodam da je časopis do kraja izlaženja objavio još i temat "U spomen Žilu Delezu”, koji je priredila Branka Arsić, temat posvećen američkoj feminističkoj kritici, koji je pod nazivom "Ginokritika: istraživanja ženske književne tradicije" priredila Biljana Dojčinović, temat "Rod i prikazivanje" koji su priredile Branka Arsić i Dubravka Đurić, temat o feminističkoj teoriji filma, kao i temat posvećen Pegi Kamuf, koje je takođe priredila Branka Arsić. Posebno smo smatrale važnim temat posvećen Radi Iveković, koji se pod nazivom "Antropologija razlike" pojavio u dvobroju 11-12. Osim opširnog razgovora sa Radom Iveković i njenog autobiografsko/teorijskog teksta "Moje audicije", za ovaj temat su dale priloge i Nadežda Čačinović, Biljana Kašić, Branka Arsić i Vesna Bogojević. Druga tema broja bio je Žak Derida. 
oblikovanju drugog talasa feminizma. Domaća produkcija zavisila je velikim delom od interesa istraživačica: prilozi dolaze iz oblasti filozofije, sociologije, književne teorije i kritike, lingvistike, teorije prava, vizuelnih umetnosti i kulturnih studija. Prema informacijama koje su stizale u Centar, časopis je bio dobro prihvaćen, ali je to ipak ostalo u neformalnoj sferi. Kao i Centar, časopis je pripadao alternativnoj kulturi i širio se neformalnim kanalima, pre svega unutar ženske mreže.

Ako o Ženskim studijama govorimo kao o časopisu sa akademskim pretenzijama, onda valja otvoriti i pitanje njegove uređivačke politike iz perspektive takozvane "provere kvaliteta", koja se u akademskim izdanjima po pravilu obezbeđuje anonimnim recenziranjem tekstova (blind peer reviewing). Iako je redakcija uvela stručnu kategorizaciju tekstova, Ženske studije nisu imale anonimno recenziranje. Pitanje anonimnog recenziranje vraća nas na pitanje kolektiviteta. Prva pretpostavka u tom procesu jeste da recenzije tekstova pišu kolege iz struke jer su oni najpozvaniji da procene vrednost novih istraživanja. No, kako kaže Brit Holbrok, ${ }^{15}$ taj proces nije tako jednostavan kako se na prvi pogled čini. Sam proces anonimnog recenziranja, koji trenutno ima neupitno središnje mesto u ocenjivanju kako naučnih projekata, tako i rezultata svih oblika naučnog rada, povezan je sa nizom pitanja koja valja imati u vidu. Ja ću ovde skrenuti pažnju samo na dva, sa kojima bi se Ženske studije nužno susrele ranih devedesetih godina. Prvo je pitanje o tome ko čini moguću zajednicu stručnjaka kvalifikovanih da procenjuju akademske dosege novih istraživanja u nekoj oblasti. Holbruk pojašnjava da je uobičajeni odgovor na to pitanje taj da "disciplina određuje ko su peers", dakle stručnjaci koji pripadaju istom krugu. Tu dolazimo do drugog problema - evaluacije, koja je u interdisciplinarnim područjima kakve su rodne studije još komplikovanija nego što je to slučaj sa tradicionalnim disciplinama.

Izdvajam ovde upravo ova dva problema kako bih ukazala na posebnosti vremena u kom su pokrenute Ženske studije. Feministička teorija nije bila novina na prostoru Jugoslavije. Sve ženske grupe koje su nastale početkom devedesetih godina oslanjale su se na to nasleđe. To je, naravno, važilo i za beogradski Centar i za časopis Ženske studije. Postojanje te tradicije dovelo je feministkinje sa jugoslovenskih prostora u poseban, možda čak i privilegovan položaj u odnosu na žene iz drugih postsocijalističkih zemalja koje su imale mnogo manje dodira sa drugim talasom feminizma. U odnosu na njih, feministkinje sa postjugoslovenskih prostora imale su iza sebe i korpus

15 J. Britt Holbrook, “Peer Review”, The Oxford Handbook of Interdisciplinarity, ed. Robert Frodeman et al., Oxford University Press, 2010, str. 321-332. 
prevedenih ključnih tekstova i objavljene knjige domaćih autorki. ${ }^{16}$ To nasleđe bilo je ugrađeno u optimizam sa kojim smo krenule u projekat disciplinizacije ženskih studija.

Kada je reč o institucionalizaciji novih disciplina, postoje dva osnovna modela. Prvi je takozvani "pritisak odozdo", do kog dolazi kada u novom području postoji veliki broj zainteresovanih pojedinaca koji proizvode znanje i očekuju da se to znanje na neki način legitimizuje. Drugi je takozvani "pritisak odozgo", kada državne ili akademske institucije otvaraju nove odseke i promovišu nove discipline iz političkih ili pragmatičnih razloga. Ulazak ženskih studija na univerzitete početkom sedamdesetih godina, prvo u Americi, a potom i u nekima od evropskih zemalja, dogodio se zahvaljujući pritisku "odozdo", odnosno pojavi velikog broja istraživačica koje su započele sa sistematskim radom u tom području. One su prvo zahtevale legitimnost za nove teme istraživanja, potom su uvodile nove kurseve i organizovale se $\mathrm{u}$ istraživačke centre koje promovišu ženske i rodne studije, da bi na kraju akreditovale i cele programe. Ti procesi nisu bili ni laki ni jednostavni, a na neki način oni traju do danas. ${ }^{17}$ Feministkinje su u međuvremenu naučile da koriste oba modela. ${ }^{18}$

U beogradskom Centru za ženske studije očekivale smo da bi zajednički rad oba modela mogao da dovede do uspeha, kao i da bi časopis koji pokazuje relevantnost feminističke teorije, ali i relevantnost domaće produkcije u tom području, u tome mogao da ima važnu ulogu. Recenziranje nije bilo deo tog inicijalnog projekta jer su ratovi za jugoslovensko nasleđe otežali komunikaciju među feministkinjama sa tog prostora (iako veze nikada nisu bile prekinute); drugim rečima, novouspostavljene granice podelile su tako i kolektivitet feminističkih istraživačica. S druge strane, u okviru lokalnih scena, oblikovao se jedan novi kolektivitet koji su činile sve žene koje su se na neki način bavile feminizmom i feminističkom teorijom, i ta otvorenost je bila neobično važna. Centar za ženske studije je bio pre svega obrazovni i istraživački projekat, ali je održavao blisku vezu sa radom Autonomnog ženskog centra, Žena u crnom i drugih

$16 \mathrm{U}$ tom smislu posebno je informativna Odabrana bibliografija radova iz feminističke teorije / ženskih studija 1974-1996, koju je priredila Biljana DojčinovićNešić za Centar za ženske studije i komunikaciju.

17 Tako se u proteklih desetak godina u Velikoj Britaniji zatvorilo nekoliko programa rodnih studija. Poslednji primer je ukidanje prvo dodiplomskih, a potom i poslediplomskih studija na Univerzitetu u Halu.

18 Zanimljiv je, recimo, primer Španije, koja ima vrlo rigidan, disciplinarno čvrsto postavljen sistem univerziteta. Ženske studije su dobile formalnu akreditaciju kao zaseban akademski program tek zahvaljujući programu Erasmus Mundus. 
ženskih grupa koje su u svojim izdanjima objavljivale i aktivističke i teorijske tekstove, pokazujući koliko su oni duboko povezani. Projekat legitimizacije ženskih studija na mnogo načina je trebalo da bude zajednički projekat svih ženskih grupa, projekat legitimizacije ženskog znanja i subverzije patrijarhalnog modela moći koji je bio temelj za nacionalizam i ratove.

Ta karakteristična veza aktivizma i teorije bila je značajna odlika feminističke scene na celom post-jugoslovenskom prostoru. Tako je Centar za ženske studije u Zagrebu, koji je jedno vreme ozbiljno razmatrao mogućnost ulaska na Filozofski fakultet, odustao od tog projekta kako bi sačuvao svoj specifični karakter akademske i aktivističke organizacije. Centar se za ulazak u sistem visokog obrazovanja pripremao vrlo ozbiljno, pa je tako sprovedeno i akademsko istraživanje Ženski/Rodni studiji - integracija u hrvatski sveučilišni sustav. Na temelju tog istraživanja nastao je obuhvatan zbornik koji su uredile Valerija Barada, Juliette Janušić, Biljana Kašić, Jasminka Pešut, ${ }^{19} \mathrm{u}$ kojem su obrađeni različiti aspekti procesa institucionalizacije ženskih studija, od teorijskih do praktičnih. Zbornik donosi i primere institucionalizacije iz takozvane Zapadne Evrope, ali i snimak situacije u takozvanim tranzicijskim zemljama. U jednom od priloga iz zbornika, sažimajući dato stanje, Biljana Kašić kaže:

2003. godine nalazimo se u jednoj začudnoj situaciji. Čini se da Ženski studiji kreiraju jedan tip drukčijeg projekta, zahtjevan i oslobađajući od klišeiziranog "standardiziranja”. Ženski studiji u Zagrebu, započeti 1995. godine, zapravo su program kritičkog čitanja (znanosti, zbilje, ikonografije, literature, medija, vizualnih znakova, tijela, stereotipa), ali i studiji osvještavanja.

No, cijelo je vrijeme prisutna dilema s početka ovog izlaganja. Do kojih je razmjera moguće afirmirati spoznaju na Ženskim studijima koji uživaju "privilegiju" margine u kontekstu u kojem ženski studiji nisu ovjereni kao polje spoznaje, a nisu razgovjetni ni otpori? ${ }^{20}$

Situacija koju Biljana Kašić ovde opisuje bila je i situacija časopisa Ženske studije.

19 Institucionalizacija Ženskih studija u Hrvatskoj - akcïsko istraživanje, Centar za ženske studije, Zagreb, 2003, http://zenstud.hr/library/institucionalizacijazenskih-studija-uhrvatskoj-akcijsko-istrazivanje/.

20 Isto, str. 121. 


\section{ČASOPIS "EUROPEAN JOURNAL OF WOMEN'S STUDIES": ŽENSKO ISKUSTVO IZ EVROPSKE PERSPEKTIVE}

Kada se pogleda šira akademska scena, pre svega u Evropi i Severnoj Americi, postaje očigledna veza između ulaska ženskih studija na univerzitete i pojave uticajnih akademskih časopisa. Jedan od najznačajnijih časopisa u domenu ženskih studija/rodnih studija Signs pokrenut je još davne 1975. godine, u vreme kada su se prvi predmeti iz ove oblasti uvodili na američkim univerzitetima. Kako stoji u uvodniku za prvi broj, namera časopisa je bila da objavljuje novo akademsko znanje o ženama. Njegov cilj će biti da doprinese "stvarnom razumevanju muškaraca i žena, pola i roda, i važnih obrazaca ljudskog ponašanja, institucija, ideologija i umetnosti”. ${ }^{21}$ Uvodnik takođe naglašava da je namera časopisa da neguje interdisciplinarni pristup, čime je Signs među prvima afirmisao upravo ovu osobinu akademske proizvodnje ženskog znanja. Drugi značajan časopis za oblikovanje američke i međunarodne akademske scene bio je časopis za feminističku filozofiju Hypatia, pokrenut 1986. godine. Hypatia je disciplinarno utemeljen časopis, ali sa jasnim feminističkim određenjem, čija je namera bila da doprinese "razumevanju i okončanju seksističke represije nad ženama i shvatanju uloge filozofije u tom procesu". ${ }^{22}$

Istorija disciplinizacije ženskih studija u Evropi u početku je bila određena posebnim politikama nacionalnih država. Međutim, sa širenjem uloge i značaja Evropske unije, sa kreiranjem obrazovnih politika koje prevazilaze granice nacionalnih država, sa stvaranjem otvorenijeg (što još uvek ne znači i zajedničkog) akademskog prostora (i tržišta), došlo je do stvaranja evropski orijentisanih feminističkih časopisa. Za mene je posebno zanimljiv primer Evropski časopis za ženske studije (European Journal of Women's Studies, EJWS ), pokrenut u Londonu 1994, to jest, u isto vreme kada su u Beogradu osnovane Ženske studije. Časopis je pokrenut sa namerom da bude platforma za istraživanja u oblasti ženskih studija i rodnih studija, ali i da to čini iz jedne karakteristično evropske perspektive. U tom smislu, pokretanje časopisa bilo je povezano sa višestruko isprepletenim složenim procesima: od jačanja i, istovremeno, preispitivanja evropskog državnog i kulturnog identiteta, preko uvođenja takozvanog "bolonjskog procesa" koji ce suštinski promeniti visoko obrazovanje

21 Catharine R. Stimpson, Joan N. Burstyn, Domna C. Stanton, and Sandra M. Whisler, "Editorial", Signs: Journal of Women in Culture and Society, no. 1 (Autumn, 1975), v-viii. https://doi.org/10.1086/493202, pristupljeno 1. 05. 2018.

22 Hypatia: A Journal for Feminist Philosophy, 1986, Vol. 1, Issue 1, p. 1, https:// doi.org/10.1111/j.1527-2001.1986.tboo519.x pristupljeno 1. 05. 2018. 
u Evropi, do pitanja disciplinizacije ženskih studija na novom, reformisanom univerzitetu. Zbog toga ovaj časopis kontinuirano otvara dve velike teme: s jedne strane, pitanje proizvodnje ženskog znanja i njegovog statusa u akademskim okvirima; s druge strane, pitanje mogućeg evropskog identiteta ženskih studija kao akademske discipline.

Obe teme prisutne su u uvodnom tekstu koji su za prvi broj EJWS napisale prve glavne i odgovorne urednice, Meri Evans i Kia Tijdens, naglasivši da je s padom berlinskog zida promenjena slika Evrope i otvorena mogućnost za žene sa čitavog kontinenta da zajedno traže odgovore na pitanja koja smatraju bitnima. One posebno naglašavaju krizu društvenih sistema na Zapadu i potrebu žena da kritički promisle moguće alternative:

Te alternativne politike su ono što mi vidimo kao ključno za ovaj časopis. Pojam "evropski” tako ovde ima dva značenja; prvo, doslovno značenje Evrope kao tla, ali i složenije, metaforičko značenje novog političkog poretka u kojem će postati moguce ponovno pregovaranje i preuređivanje vekovima starih granica i izvesnosti. Kroz razmenu ideja i informacija nadamo se da ce postati moguće stvaranje političke agende koja bi vodila uspostavljanju, u javnoj sferi, politike koju stvaraju žene i koja jeste za žene. ${ }^{23}$

Urednice ističu da im je važna saradnja ne samo sa ženama iz svih delova Evrope, već i iz različitih institucija. Časopis od početka objavljuje anonimno recenzirane tekstove, a pitanje interdisciplinarnosti i multikulturalnosti, koje kombinovano može predstavljati problem za recenzente, rešavao se tako što se jedna recenzija tražila iz oblasti iz koje je rađeno istraživanje, a druga iz nacionalne sredine iz koje potiče istraživačica.

Sama redakcija bila je interdisciplinarna i multikulturna, sa članicama iz svih delova Evrope. Budući da se Evropa u EJWS nikada nije poistovećivala sa Evropskom unijom, redakcija je od početka uključivala i članice izvan okvira Unije. U jednom trenutku, bila sam pozvana da se pridružim uredništvu kao neko ko dolazi sa prostora takozvane Istočne Evrope. Bila sam članica redakcije od 1998. do 2009. godine. To iskustvo mi je takođe važno za poređenje dva časopisa - Ženskih studija i EJWS, jer sam tada videla svu razliku između partizanskog uređivanja časopisa koji zavisi od donacija i uređivanja

23 “Editorial”, European Journal of Women's Studies, Vol. 1, Issue 1, May 1994. http://journals.sagepub.com/toc/ejwa/1/1, pristupljeno 12. 04. 2018. 
časopisa iza koga stoji velika izdavačka kuća, veliko tržište i veliki broj zainteresovanih saradnika i čitalaca. Osnov (finansijske) stabilnosti EJWS bile su pretplate univerzitetskih biblioteka, kojima se ujedno podržavao akademski ugled časopisa. Tu, naravno, treba uzeti u obzir razliku između malih i velikih jezika jer je $E J W S$, kao časopis koji izlazi na engleskom jeziku, mogao da računa na široku međunarodnu publiku, dok su Ženske studije ostajale vezane za mnogo manji prostor. Ipak, ovde nije reč samo o tome, već i o činjenici da bez sistemske podrške biblioteka časopisi teško mogu da opstanu. Dok smo se mi u Beogradu suočavale sa posledicama razaranja bibliotekarske mreže, knjižarske mreže i tržišta knjiga, što je značilo da Ženske studije, koliko god kvalitetne bile, ostaju izvan sistema biblioteka (posebno onih univerzitetskih), dotle je za distribuciju EJWS brinuo izdavač, postavljajući časopis u istu ravan sa časopisima iz drugih oblasti. Ta razlika u statusu časopisa istovremeno je ilustrativna za razliku u statusu discipline: u Velikoj Britaniji i kasnije Evropskoj Uniji istraživanja iz oblasti ženskih studija bila su prepoznata kao deo akademske proizvodnje znanja, dok su beogradske Ženske studije delile sudbinu Centra za ženske studije kao alternativno glasilo alternativnog obrazovnog centra.

Evropski časopis za ženske studije od početka je bio povezan sa Evropskom asocijacijom ženskih studija (European Women's Studies Association, WISE), i to je ostao do danas, samo što je WISE zamenila druga organizacija, AtGender, koja okuplja i institucije i pojedince. ${ }^{24} \mathrm{U}$ tom smislu, EJWS kontinuirano participira u procesu kreiranja onoga što bismo mogli da nazovemo evropski kolektivitet feminističkih subjekata, što znači i da kontinutirano promišlja svoj evropski karakter. Govoreći o tome iz perspektive dvehiljaditih godina, Mari Evans i Keti Dejvis (koja je nakon prvih nekoliko godina zamenila Kiu Tijdens) naglašavaju procesualnost tog promišljanja:

[O]drediti šta bi moglo konstituisati "evropsko feminističko znanje" nije neproblematičan poduhvat. Tokom poslednje dekade mi smo se u časopisu trudile da dođemo do nečega što ne bi bila defanzivna lokacija, poput "ne-US Amerikanca”. Granice Evrope su danas ozbiljno dovedene u pitanje, isto onako kao što je to bilo i u prošlosti. I dok je časopis u početku zauzeo pragmatičan stav da prihvata svaki tekst koji bi mogao - koliko

24 Ovde, naravno, vredi primetiti i promenu naziva od ženskih studija u rodne studije. Detalji o organizaciji AtGender, koja se definiše kao Evropska asocijacija za rodna istraživanja, edukaciju i dokumentaciju mogu se naći na internet strani atgender.eu. 
god rubno - da se poveže sa Evropom (bilo preko autorkinog nacionalnog porekla, institucionalne lokacije ili preko teme), s vremenom smo sve više uviđale kako je funkcija časopisa upravo u propitivanju konstrukcije same Evrope. (...) Počele smo da uočavamo da, kao evropski časopis, treba da situiramo Evropu - njenu istoriju, njene institucije, njene političke pokrete, njenu kulturnu produkciju - u globalni kontekst, da ne mislimo samo o onome što se dešava “ovde", već i o načinima na koje Evropa jeste - i uvek je bila - povezana sa drugim delovima sveta. ${ }^{25}$

Ovaj put od propitivanja granica Evrope do propitivanja Evrope u globalnom kontekstu na mnogo načina korespondira sa razvojem feminističke teorije u poslednjih dvadeset godina, od teorija razlike do transnacionalnog feminizma. Kao što naglašavaju njegove urednice, časopis se od početka postavio u odnos istovremene opozicije prema i dijaloga sa američkom feminističkom teorijom, koja se još od sedamdesetih godina nametnula kao skoro isključivi sinonim za feminističku teoriju. EJWS američkoj teoriji ne želi da suprotstavi (samo) etablirane evropske vrednosti poput francuske ili britanske teorije iz sedamdesetih godina, već i da istraži ono što nastaje u Evropi i u vezi sa Evropom, polazeći od na prvi pogled jednostavnog pitanja: da li uopšte postoji ono što bismo mogli da nazovemo "evropski feminizam"? Odgovor se očito nije tražio u dominaciji jednog teorijskog modela ili struje mišljenja, već u konstituisanju zajednice onih koji se na neki način bave pitanjima Evrope, pre svega iz kritičke vizure. Drugim rečima, odgovor na pitanje "šta je Evropa" tražen je kroz kritičko promišljanje pitanja šta Evropa nije i ne bi smela da bude.

Druga definišuća odrednica časopisa bila je politička odluka da se ime časopisa veže uz "ženske studije”, očito u kontekstu šireg preispitivanja statusa "ženskih studija" u odnosu prema tada sve raširenijoj praksi imenovanja akademskih programa odrednicom "rodne studije”. Tako se kao prvi tekst u prvom broju časopisa pojavljuje obimna analiza Dijane Ričardson i Viktorije Robinson aktuelnih politika imenovanja obrazovnih programa i njihovih implikacija. ${ }^{26}$ Autorke

25 Cathy Davis and Mary Evans, "Introduction - Transatlantic Conversations: Feminism as Traveling Theory", u: Transatlantic Conversations: Feminism as Traveling Theory, eds. Cathy Davis and Mary Evans (Farnham, England and Burlington, Vermont: Ashgate, 2011), str. 6.

26 Diane Richardson i Victoria Robinson, “Theorizing Women's Studies, Gender Studies and Masculinity: The Politics of Naming”, European Journal of Women's Studies 1(1), May 1994, str. 11-27. 
donose obuhvatan pregled praksi imenovanja, argumenata koji se uz njih vezuju i problema koji se pojavljuju u upotrebi dva termina, "žensko" i "rodno", uključujući i probleme sa njihovim prevođenjem na različite evropske jezike. Analizirajući polemiku koja se početkom devedesetih godina razvila $\mathrm{u}$ akademiji oko politike imenovanja, autorke indikativno citiraju Meri Evans, koja smatra da je rod neutralan termin koji skreće pažnju sa problema nejednakosti koje proizvode seksualne razlike. ${ }^{27}$ I one same na kraju svoje analize zaključuju kako težnja da se "ženske studije" preimenuju u "rodne studije" znači njihovu deradikalizaciju. Zanimljivo je, međutim, da one ostavljaju i određeni prostor sumnje jer završavaju pitanjem da li njihovi argumenti važe i za žene u drugim evropskim kontekstima. ${ }^{28}$

Ovo završno pitanje istovremeno se može čitati i kao otvaranje prema teorijama razlike, koje će obeležiti devedesete godine. Časopis je kroz skoro 25 godina svog postojanja pratio glavne teorijske tokove, ali je uvek ostajao veran svom feminističkom političkom utemeljenju, interesovanju za žene i njihovo iskustvo. U tom smislu, sociološke i antropološke analize su od početka imale prevagu, iako je časopis bio otvoren i za teme iz humanistike, primarno iz oblasti književnosti i umetnosti. Autorke su dolazile iz svih delova geografske Evrope, a časopis je posebno pratio status ženskih studija i na taj način doprinosio njihovoj disciplinizaciji.

Časopis je redovno objavljivao prikaze knjiga i liste novih izdanja, doprinoseći i na taj način razumevanju širine i složenosti istraživanja u području ženskih studija. Bavio se teorijom, ali je u celini bio više okrenut ženskom iskustvu i načinima na koji se to iskustvo ugrađuje u proizvodnju ženskog znanja. U tom smislu, mnogi tekstovi su postavljali i pitanje metoda, što je bila tema kojom se beogradske Ženske studije zapravo nisu mnogo bavile.

Svake godine, EJWS je objavljivao jedan tematski broj, koji su po pravilu uređivale članice redakcije. Izbor tema je odražavao zajedničku procenu relevantnosti tema koje bi valjalo posebno obraditi. Tako je časopis u prvih deset godina objavio specijalne brojeve posvećene porodici (1994), tehnologiji (1995), telu (1996, 1997), ideji Evrope (1998), Simon de Bovoar (1999), ženama i migraciji (2000), lezbejstvu (2001), ženskom prostoru (2001), te problemu granice (2003).

27 Isto, str. 17.

28 Isto, str. 25-26. 
Iz današnje perspektive može se reći da EJWS zagovara intersekcionalnost kao teorijsko i metodološko uporište akademskog feminizma. Sudeći po rubrici "Online First", ${ }^{29}$ sledeći tematski broj biće posvećen ponovnom tumačenju pojma ženskosti iz perspektive novih feminističkih teorija.

\section{UMESTO ZAKLJUČKA: ŽENSKE STUDIJE KAO INTERDISCIPLINARNA DISCIPLINA}

U ovoj uporednoj analizi dva časopisa sličnog naziva i samo donekle slične koncepcije pokušala sam da se osvrnem na probleme disciplinizacije ženskih studija i ulogu koju časopisi imaju u tim procesima. Oba primera kojima sam se ovde bavila zapravo teže da doprinesu disciplinizaciji, dakle akademskom prepoznavanju i priznavanju jedne oblasti na koju danas često referišemo zajedničkom odrednicom ženske studije/rodne studije. Podela na dve oblasti, barem kada je reč o Evropi, nije se pokazala produktivnom. Istorija dva časopisa bila je vrlo različita iz mnogo razloga, pre svega kontekstualnih, od veličine jezika do materijalnih i akademskih uslova u kojima su dva projekta nastajala i razvijala se.

Za oba časopisa je, međutim, zajednička svest o značaju multidisciplinarnosti i interdisciplinarnosti za akademsko utemeljivanje i legitimizaciju ženskog znanja. Jedna od velikih debata koja se vodila u Evropi u vezi sa statusom ženskih studija odnosila se na pitanje o tome da li treba osnivati posebne katedre ili "feminizovati”, odnosno "orođavati" discipline "iznutra”. Zemlje severa Evrope, Nemačka, Holandija i Velika Britanija, odlučile su se za osnivanje katedri. Tim su putem krenule i neke postsocijalističke zemlje. Francuska, Italija i Španija prihvatile su drugi princip - "orođavanje” iznutra. Iskustvo je u međuvremenu pokazalo da je postojanje posebnih katedri za ženske studije/rodne studije moćno oruđe za proizvodnju ženskog znanja. Iako su te katedre po pravilu male i često izolovane, kada se jednom uspostave, teže im je oduzeti legitimitet i izbrisati ih iz naših akademskih i intelektualnih istorija. Te katedre mogu postojati samo ako ženske studije/rodne studije prepoznajemo kao "interdisciplinarne discipline". Za tu vrstu dijaloga, bez kog nema profesionalnog kolektiviteta, niti razvoja discipline, interdisciplinarni časopisi su nužan preduslov.

Međutim, ostaje otvoreno jedno mnogo šire pitanje o prirodi univerziteta danas, o tome šta se dogodilo sa univerzitetom tokom ne-

29 http://journals.sagepub.com/toc/ejwa/o/o, pristupljeno 14. 04. 2018. 
koliko decenija oblikovanja ženskih studija/rodnih studija kao akademske discipline, i koja će biti uloga časopisa u kritičkom praćenju tih zbivanja. Navešću stoga, umesto zaključka, jedan zanimljiv primer koji donosi $E J W S$, a koji povezuje neke od bitnih tema u ovom tekstu. Reč je prilogu Rozmari Baukeme i Iris van der Tuin o statusu rodnih studija na korporatizovanom univerzitetu u Evropi. ${ }^{30}$ Analizirajući proces neuspešnog konkurisanja za novac za istraživanje kod evropskih fondova, Baukema i van der Tuin pokazuju da se institucionalizacijom sigurnosna kapija ne otvara, već pomera, prava moć se seli tamo gde su izvori novca, a za sve to je bitna uloga naizgled objektivnog anonimnog recenziranja u tom procesu. One naglašavaju da je korporatizovani univerzitet otvorio izvestan prostor za rodne studije, ali da se istovremeno i sam univerzitet promenio stavljajući u prvi plan zakonitosti ekonomskog determinizma. Time se nužno promenila i logika vrednovanja akademskih postignuća. Tako se, na jednoj strani, otvara pitanje do koje mere nov model korporatizovanog univerziteta utiče na feminističku epistemologiju, a na drugoj, kako nova načela vrednovanja utiču na feministička istraživanja. ${ }^{31}$ Baukema i van der Tuin navode kao primer sopstvenu prijavu na kojoj je radilo nekoliko univerziteta i na koju je potrošeno oko 1000 radnih sati, a koja na temelju anonimnih recenzija na kraju nije dobila potporu ne zbog akademske izvrsnosti, već zbog drugih razloga. Autorke zaključuju kako su rodne studije prihvatljivije za institucije kada pojam roda koriste kao "statističku kategoriju", umesto kao analitičku kategoriju, što pokazuje da rodne studije u Evropi još uvek nisu potpuno integrisane u akademiju jer nemaju "moć definisanja". ${ }^{2}$ Baukema i van der Tuin se ne zalažu za alternativnu poziciju. Ako je slogan Elen Siksu u sedamdesetima bio "žene, pišite", onda je njihov odgovor danas "žene, uđite u akademiju i istražujte", ali tako da sistem ne bude korak ispred vas.

30 Rosemarie Buikema i Iris van der Tuin, "Doing the document: Gender studies at the corporatized university in Europe", u: European Journal of Women's Studies 20(3), str. 309-316.

31 Isto, str. 312.

32 Rosemarie Buikema i Iris van der Tuin, "Doing the document: Gender studies at the corporatized university in Europe, Part 2: Answering the Sixty-four thousand dollar question”, u: European Journal of Women's Studies 21(2), str. 196. 


\section{LITERATURA}

Blagojević, Marina, ur. Ka vidljivoj ženskoj istoriji: Ženski pokret $u$ Beogradu 9o-tih. Beograd: Centar za ženske studije, istraživanje i komunikaciju, 1998.

Buikema, Rosemarie and Iris van der Tuin. "Doing the document: Gender studies at the corporatized university in Europe". European Journal of Women's Studies 20(3).

Buikema, Rosemarie and Iris van der Tuin. "Doing the document: Gender studies at the corporatized university in Europe, Part 2: Answering the Sixty-four thousand dollar question”. European Journal of Women's Studies 21(2).

Davis, Cathy and Mary Evans. "Introduction - Transatlantic Conversations: Feminism as Traveling Theory". Transatlantic Conversations: Feminism as Traveling Theory. Eds. Cathy Davis and Mary Evans. Farnham, England and Burlington, Vermont: Ashgate, 2011.

Dojčinović, Biljana. “Centar za ženske studije”. Ka vidljivoj ženskoj istoriji: Ženski pokret u Beogradu 9o-tih. Prir. Marina Blagojević. Beograd: Centar za ženske studije, istraživanje i komunikaciju, 1998.

Đurić, Dubravka. "Feministička izdavačka delatnost”. Ka vidljivoj ženskoj istorïi: Ženski pokret u Beogradu 9o-tih. Prir. Marina Blagojević. Beograd: Centar za ženske studije, istraživanje i komunikaciju, 1998.

“Editorial”. European Journal of Women's Studies. Vol. 1, Issue 1, May 1994. http://journals.sagepub.com/toc/ejwa/1/1, pristupljeno 12. 04.2018.

Hypatia: A Journal for Feminist Philosophy, 1986, Vol. 1, Issue 1. https://doi.org/10.1111/j.1527-2001.1986.tbo0519.x, pristupljeno 1. 05. 2018.

Kašić, Biljana i Sandra Prlenda. "Yugoslav Feminists in Socialism". Genero, broj 19, str. 27-48. https://www.ceeol.com/search/articledetail?id=478515, pristupljeno 12. 04. 2018.

Kašić, Biljana, Jasminka Pešut, Valerija Barada, Juliette Janušić. Institucionalizacija Ženskih studija u Hrvatskoj - akcijsko istraživanje, Centar za ženske studije, Zagreb, 2003, http://zenstud.hr/library/ institucionalizacija-zenskih-studija-uhrvatskoj-akcijsko-istrazivanje/

Lorand, Zsofia. "Learning a Feminist Language: The Intellectual History of Feminism in Yugoslavia in the 1970s and 1980s". Doktorska teza, Central European University, 2015. 
Lukić, Jasmina. "Ženski studiji kao mjesto susretanja/ presjeka disciplina”. Treća 1-2, Vol. VII, 2005. http://zenstud.hr/wp-content/ uploads/2017/o1/Treca_br2_2005.pdf, pristupljeno 12. 04. 2018.

Mlađenović, Lepa. "Počeci feminizma - Ženski pokret u Beogradu, Zagrebu, Ljubljani”. http://www.womenngo.org.rs/zenski-pokret/ istorija-zenskog-pokreta/217-poceci-feminizma-zenski-pokret-ubeogradu-zagrebu-ljubljani.

Papić, Žarana. "Women in Serbia: Post-Communism, War, and Nationalist Mutations". Gender Politics in The Western Balkans. Ed. Sabrina Ramet. Philadelphia: The Pennsylvania University Press, 1999.

Richardson, Diane and Victoria Robinson. "Theorizing Women's Studies, Gender Studies and Masculinity: The Politics of Naming". European Journal of Women's Studies 1(1), May 1994, str. 11-27.

Stimpson, Catharine R., Joan N. Burstyn, Domna C. Stanton, and Sandra M. Whisler. "Editorial". Signs: Journal of Women in Culture and Society, no. 1 (Autumn, 1975). https://doi.org/10.1086/493202, pristupljeno 1. 05. 2018.

Turner, Stephen. "What are Disciplines? And How Is Interdisciplinarity Different?”. Practicing Interdisciplinarity. Eds. Peter Weingart, Nico Stehr. Toronto: University of Toronto Press, 2000.

Vušković, Lina i Sofija Trivunac. "Feministička grupa Žena i društvo". Ka vidljivoj ženskoj istorïi: Ženski pokret u Beogradu 9o-tih. Prir. Marina Blagojević. Beograd: Centar za ženske studije, istraživanje i komunikaciju, 1998.

\section{THE ROLE OF FEMINIST SCHOLARLY JOURNALS: WOMEN'S/GENDER STUDIES AND THE PROBLEM OF DISCIPLINES}

This article describes and analyses the history of the Women's Studies Centre in Belgrade, together with the history of publishing of its first journal - Ženske studije / Women's Studies (1995-2002). The author discusses the editorial politics in the journal Ženske studije, together with its role in the process of legitimizing the women's knowledge and experience. Feminist journals are seen as promoters of the feminist theory in the post-Yugoslav region. The article highlights the significance of the journals in the process of institutionalizing the programmes 
in the Women's/Gender Studies. Besides this, the author offers comparative analysis of two feminist journals - Ženske studije and European Journal of Women's Studies.

Keywords: Ženske studije/Women's Studies, European Journal of Women's Studies, Women's/Gender Studies as “interdisciplinary discipline”, feminist journals, editorial politics 